\title{
Treatment Strategies and Outcomes of Medication Related Osteonecrosis of the Jaw (MRONJ)
}

\author{
Gol EB* \\ Department of Oral and Maxillofacial Surgery, Samsun Oral and Dental Health Hospital, Turkey
}

\begin{abstract}
Medication Reliated Osteonecrosis of The Jaws (MRONJ); Caused by maxillofacial surgical procedures performed during or after antiresorptive, antiangiogenic and bisphosphonate treatments; It is a newly defined disease and its etiopathogenesis is still not fully understood. Studies on the definition, staging and treatment approaches of the disease are evaluated by the commission formed by the American Association of Maxillofacial Surgeons, and guidelines expressing opinions on these issues are published; Discussions still continue on the treatment approaches of the disease. Conservative, surgical, alternative and their combinations methods are used in the treatment of the disease, depending on the level of bone and soft tissues affected.
\end{abstract}

Keywords: Bisphosphonates, MRONJ, Outcomes, Management

\section{Introduction}

Bisphosphonates (BPs) represent a group of drugs used in various disciplines such as endocrinology, oncology, and orthopedics. ${ }^{1,2}$ They are often used for the treatment of bone diseases such as osteoporosis, Paget's disease, malignant hypercalcemia, osteolytic bone metastases and osteolytic lesions of mutiple myeloma. ${ }^{1,3,4}$ They reduce the need for radiotherapy and surgery by providing a statistically significant reduction in skeletal complications, including pathological fractures, spinal cord compression, and malignant disease hypercalcemia. ${ }^{5}$

BPs are synthetic analogs of the natural pyrophosphate molecule. They can be classified according to whether or not they contain nitrogen, and it is known that nitrogen-containing BPs have higher potential than those without nitrogen content. ${ }^{6}$

The first lesion in the jaws after long-term BP use was described by Marx in 2003. ${ }^{7}$ Bisphosphonate-related osteonecrosis of the jaws (BRONJ) is considered the main side effect of BP treatment. ${ }^{8,9}$

Recently, osteonecrosis of the jaw was encountered with oncological doses of other antiangiogenic (sunitib) or antiresorptive (denosumap) agentswithout use of BPs. ${ }^{10-12}$ This condition caused the name and definition of the disease to change, and a new definition was made by AAOMS (American Association of Oral and Maxillofacial Surgeons) in 2014. This definition is formulated as follows: "Without application of radiotherapy to the jaw and bone metastasis in the jaws; open necrotic bone or bone necrosis with intra-oral or extra-oral fistula for 8 weeks or longer despite being treated by a clinician in the maxillofacial region, with the previous or current use of antiresorbtive and antiangiogenic agents. ${ }^{13}$

The true incidence of MRONJ is not known exactly. Reported rates range from $0.028 \%$ to $18.6 \%$, depending on the indication of treatment, study population and sample size. ${ }^{14,15}$

\section{MRONJ: Diagnosis and Staging}

Patient history and clinical examination remain the most sensitive diagnostic tools for MRONJ. Despite the treatments performed, the presence of exposed bone in the oral area for 8 weeks or longer is the most consistent diagnostic criteria for MRONJ. ${ }^{16}$ Differential diagnosis of BRONJ should be made from previously defined and known clinical pathologies such as alveolar osteitis, sinusitis, gingi-

\begin{tabular}{|l|l|}
\hline Quick Response Code: & *Corresponding author: Esma Bilge GÖL, Department of Oral and Maxillofacial Surgery, \\
Samsun, Turkey \\
Received: 31 May, 2021
\end{tabular}


vitis / periodontitis, periapical pathologies and some sequestering forms of cemento-osseous dysplasia. ${ }^{16}$

Open and necrotic areas of bone may remain asymptomatic for weeks, months or even years. ${ }^{17}$ These lesions often become symptomatic following infection of the surrounding tissues. Clinically, signs and symptoms including pain, mobility of teeth, mucosal swelling, erythema, ulceration, paresthesia, even anesthesia of the relevant trigeminal nerve branch may precede the development of osteonecrosis. ${ }^{18,19}$ In some patients, impaired sensory perception may occur in the relevant region due to the compression of the resulting infection on the neurovascular bundle. ${ }^{20,21}$ These symptoms may occur spontaneously or mostly occur after dentoalveolar surgery. ${ }^{22-27}$

In many MRONJ patients, the radiological findings are within normal limits or are similar to those seen in osteoradionecrosis or osteomyelitis.

The first classification of MRONJ was made by Marx in 2009 based on the clinical appearance of the disease. ${ }^{28}$ This classification was formalized in a report published by AAOMS in the same year. ${ }^{29}$ Five separate stagings have been made in this classification (Table 1).

Table1: Staging and Treatment Strategies of BRONJ (Ruggiero 2014).

\begin{tabular}{|c|c|c|}
\hline BRONJ Stage & Clinical Appearance & Treatment Strategies \\
\hline At Risk & $\begin{array}{l}\text { No apparent necrotic bone in patients who have been treated } \\
\text { with oral or intravenous bisphosphonates }\end{array}$ & $\begin{array}{l}\text {-No treatment indicated } \\
\text {-Patient education }\end{array}$ \\
\hline Stage 0 & $\begin{array}{l}\text { No clinical evidence of necrotic bone but nonspecific clinical } \\
\text { findings, radiographic changes, and symptoms }\end{array}$ & $\begin{array}{l}\text {-Systemic management, including use of pain medicati- } \\
\text { on and antibiotics }\end{array}$ \\
\hline Stage 1 & $\begin{array}{l}\text { Exposed and necrotic bone or fistulas that probes to bone } \\
\text { in patients who are asymptomatic and have no evidence of } \\
\text { infection }\end{array}$ & $\begin{array}{c}\text {-Antibacterial mouth rinse } \\
\text {-Clinical follow-up on a quarterly basis } \\
\text {-Patient education and review of indications for conti- } \\
\text { nued bisphosphonate therapy }\end{array}$ \\
\hline Stage 2 & $\begin{array}{l}\text { Exposed and necrotic bone or fistulas that probes to bone asso- } \\
\text { ciated with infection as evidenced by pain and erythema in the } \\
\text { region of exposed bone with or without purulent drainage }\end{array}$ & $\begin{array}{c}\text {-Symptomatic treatment with } \\
\text {-Oral antibiotics oral antibacterial mouth rinse pain } \\
\text { control } \\
\text {-Debridement to relieve soft tissue irritation and } \\
\text { infection control }\end{array}$ \\
\hline
\end{tabular}

\section{Pathophysiology and Treatment Methods of MRONJ}

Many hypotheses have been put forward that lead to development of empirically based treatment methods for MRONJ. However, it is not possible to explain the pathophysiology of MRONJ with a single hypothesis and to use the same type of treatment for all patients. ${ }^{30}$ Although the pathophysiology of MRONJ cannot be fully explained, five different hypotheses have been suggested.

Bisphosphonates are known to reduce bone resorption by impairing osteoclast function and inducing apoptosis of osteoclasts. With these effects, they affect bone healing negatively by disrupting the bone turnover and causes osteonecrosis, especially in the jaw bones.

In addition to the use of bisphosphonates, MRONJ has developed in animal models with dental pathology. This result shows that infection and / or inflammation have an effect on the etiology of MRONJ. ${ }^{30}$

It is known that nitrogen-containing bisphosphonates (especially Zoledronate) reduce microvascular density in vivo. Impaired vacularization is known to be effective in the formation of osteonecrosis, but post-mortem histological studies showed areas of osteonecrosis with normal vascularization. Therefore, it is thought that inhibition of angiogenesis is not an etiological factor per se.

Soft tissue toxicity was the first pathophysiological hypothesis proposed for BRONJ. The demonstration of the affinity of nitrogen-containing BPs for epithelial cells is equivalent to that of bone cells in some in vitro studies hasreinforced this hypothesis. However, this hypothesis has largely lost its validity as no such effect was observed in patients using denosumab..$^{30}$

Finally, It has been demonstrated that infusion of mesenchymal stem cells or T-regulator cells prevents and attenuates BRONJ-like lesions in studies performed in animalswhere immune deficiency is effective and impaired immunity promotes the development of MRONJ. ${ }^{30}$

\section{Treatment of MRONJ}

There is no universally accepted treatment protocol for MRONJ. The methods used for treatment are varied, controversial and em- 
pirical. Three broad categories of intervention have been defined. Classical "wound healing" conservative treatment, various surgical techniques and different "supportive" treatments. These 3 approaches are often used simultaneously or in successive combinations (Table 2)..$^{29,31}$

Conservative treatment includes providing optimal oral hygiene, elimination of active dental and periodontal diseases, use of topical antibiotics and, if necessary, systemic antibiotics. Although conservative treatment is not sufficient for complete recovery, it forms the basis of MRONJ therapy, as it provides long-term disappearance of symptoms and reduction of patient complaints. ${ }^{26,32}$

The basic principle in surgical treatment is to stop the progression of the disease with conservative treatment as much as possible without starting surgical treatment. However, many studies have reported successful results with surgery. ${ }^{33-35}$

With surgery, a full thickness flap should be elevated, the exposed bone should be determined to the limits where there is no osteonecrosis and normal blood supply and it should be removed by resection. The sharp edges and corners should be rounded, and the surgical area should be closed primarily with a tension-free absorbable suture one week later. ${ }^{16,36}$ Some researchers have reported better results with surgical treatment compared to debridement and conservative treatment. ${ }^{37-39}$

Table 2: Treatment methods for BRONJ management BRONJ (Ruggiero 2009).

\begin{tabular}{|c|c|}
\hline \multicolumn{2}{|c|}{ Conservative treatment: } \\
\hline & $\begin{array}{l}\text { Disinfectant mount rinses (saline, chlorhexidine, chlorine, pe- } \\
\text { de) }\end{array}$ \\
\hline- & Antibiotic therapy (local, systemic or both) \\
\hline- & Antifungal therapy \\
\hline \multicolumn{2}{|c|}{ Surgical techniques: } \\
\hline & $\begin{array}{l}\text { Surgical debriment, sequestrum removal, surgical sinus drainage } \\
\text { edures (antrostomy) }\end{array}$ \\
\hline & $\begin{array}{l}\text { Extraction of teeth within osteonecrotic bone, management of } \\
\text { ants }\end{array}$ \\
\hline- & Bone resection \\
\hline- & Surgical wound closure, reconstructive surgery, grafts \\
\hline- & Laser-assisted surgery \\
\hline- & Fluorescense-assisted surgery \\
\hline \multicolumn{2}{|r|}{ Adjuvant non-surgical treatment strategies: } \\
\hline- & Hyperbaric oxygen therapy \\
\hline- & Pentoxifylline and tocopherol (vitamin E) \\
\hline- & Ozone therapy \\
\hline- & Low Level Laser Therapy (LLLT) for biostimulation and pain relief \\
\hline & $\begin{array}{l}\text { Er:YAG, Nd:YAG, Nd:YAP laser treatment for anti-inflammatory } \\
\text { ment }\end{array}$ \\
\hline- & Platelet-rich plasma \\
\hline- & Parathyroid hormone and teriparatide \\
\hline- & Bone Morphogenetic protein (BMP) \\
\hline
\end{tabular}

Alternative treatment methods include growth and differentiation factors that increase wound healing, autologous bone marrow stem cell transplantation into the lesion, and the use of agents such as pentoxifylline and $\alpha$-tocopherol in addition to antimicrobial therapy. In addition, autofluorescence-guided surgery and low-energy laser therapy are among the alternative therapies that have been studied recently. ${ }^{40}$

\section{Conclusion}

It is known that MRONJ is a progressive disease. There is no generally accepted treatment method for MRONJ. The clinical treatment of MRONJ is arranged according to clinical signs and symptoms. Traditional treatments still maintain their place in MRONJ treatment. However, it has been observed that the success rates of supportive treatments are higher.

\section{Acknowledgments}

None.

\section{Funding}

None.

\section{Conflicts of Interest}

Author declares that there is no conflict of interest.

\section{References}

1. Conte-Neto N, Bastos AS, Spolidorio LC, et al. Oral bisphosphonate-related osteonecrosis of the jaws in rheumatoid arthritis patients: a critical discussion and two case reports. Head Face Med. 2011;27:7.

2. Patel S, Choyee S, Uyanne J, et al. Non-exposed bisphosphonate-related osteonecrosis of the jaw: a critical assessment of current definition, staging, and treatment guide-lines. Oral Dis. 2012;18(7):625632.

3. Arantes HP, Silva AG, Lazaretti Castro M. Bisphosphonates in the treatment of meta-bolic bone diseases. Arq Bras Endocrinol Metabol. 2010;54:206-212.

4. Griz L, Caldas G, Bandeira C, et al. Paget's disease of bone. Arq Bras Endocrinol Metabol. 2006;50:814-822.

5. Lipton A, Theriault RL, Hortobagyi GN, et al. Pamidronate prevents skeletal complications and is effective palliative treatment in women with breast carcinoma and osteolytic bone metastases-long term follow-up of two randomized, placebo-controlled trials. Cancer. 2000;88:1082-1090.

6. Rogers MJ, Crockett JC, Coxon FP, et al. Biochemical and molecular mechanisms of action of bisphosphonates. Bone. 2011;49:34-41.

7. Marx RE. Pamidronate (Aredia) and zoledronate (Zometa) induced necrosis of the jaws: a growing epidemic. J Oral Maxillofac Surg. 2003;61:1115-1117.

8. Wysowski DK. Reports of esophageal cancer with oral bisphosphonate use. N Engl J Med. 2009;360:89-90.

9. Bagan JV, Jimenez Y, Murillo J, et al. Jaw osteo-necrosis associated with bisphosphonates: multiple exposed areas and its relationship to teeth extractions. Study of 20 cases. Oral Oncol. 2006;42(3):327-329.

10. Brunello A, Saia G, Bedogni A, et al. Worsening of osteonecrosis of the jaw during treatment with sunitinib in a patient with metastatic renal cell carcinoma. Bone. 2009;44:173-175.

11. Aghaloo TL, Felsenfeld AL, Tetradis S. Osteonecrosis of the Jaw in a Patient on Denosumab. J Oral Maxillofac Surg. 2010;68:959-963. 
12. Stopeck AT, Lipton A, Body JJ, et al. Denosumab Compared With Zoledronic Acid for the Treatment of Bone Metastases in Patients With Advanced Breast Cancer: A Randomized, Double-Blind Study. J Clin Oncol. 2010;28:5132-5139.

13. Ruggiero SL, Dodson TB, Fantasia J, et al. American Association of Oral and Maxillofacial Surgeons. American Association of Oral and Maxillofacial Surgeons position paper on medication-related osteonecrosis of the jaw-2014 update. J Oral Maxillofac Surg. 2014;72(10):1938-1956

14. Solomon DH, Mercer E, Woo SB, et al. Defining the epidemiology of bisphosphonateassociated osteonecrosis of the jaw: prior work and current challenges. Osteoporosis International. 2013;24(1):237-244.

15. Walter C, Al Nawas B, Grotz KA, et al. Prevalence and risk factors of bisphosphonate-associated osteonecrosis of the jaw in prostate cancer patients with advanced disease treated with zoledronate. European Urology. 2008;54(5):1066-1072.

16. Khan AA, Morrison A, Hanley DA, et al. Diagnosis and Management of Osteonecrosis of the Jaw: A Systematic Review and International Consensus. Journal of Bone and Mineral Research. 2015;30(1):3-23.

17. Allen MR, Ruggiero SL. Higher bone matrix density exists in only a subset of patients with bisphosphonate-related osteonecrosis of the jaw. J Oral Maxillofac Surg. 2009;67:1373-1377.

18. Fedele S, Porter SR, D’Aiuto F, et al. Nonexposed variant of bisphosphonate-associated osteonecrosis of the jaw: a case series. Am J Med. 2010;123:1060-1064.

19. Sharma D, Ivanovski S, Slevin M, et al. Bisphosphonate-related osteonecrosis of jaw (BRONJ): diagnostic criteria and possible pathogenic mechanisms of an unexpected anti-angiogenic side effect. Vasc Cell. 2013;5:1-5.

20. Otto S, Hafner S, Grotz KA. The role of inferior alveolar nevre involvement in bisphosphonate-related osteonecrosis of the jaw.J Oral Maxillofac Surg. 2009;67:589-592.

21. Zadik Y, Benoliel R, Fleissig Y, et al. Painful trigeminal neuropathy induced by oral bisphosphonate-related osteonecrosisof the jaw: a new etiology for the numb-chin syndrome. Quintessence Int. 2012;43:97104.

22. Ferlito S, Puzzo S, Liardo C. Preventive protocol for tooth extractions in patients treated with zoledronate: a case series. J Oral Maxillofac Surg. 2011;69:1-4.

23. Scoletta M, Arduino PG, Pol R, et al. Initial experience on the outcome of teeth extractions in intravenous bisphosphonatetreated patients: a cautionary report. J Oral Maxillofac Surg. 2011;69:456-462.

24. Barasch A, Cunha Cruz J, Curro FA, et al. Risk factors for osteonecrosis of the jaws: a case control study from the CONDOR dental PBRN. J Dent Res. 2011;90:439-444.

25. Schubert M, Klatte I, Linek W, et al. The Saxon bisphosphonate register - therapy and prevention of bisphosphonate-related osteonecrosis of the jaws. Oral Oncol. 2012;48:349-354.

26. Saad F, Brown JE, C Van Poznak, et al. Incidence, risk factors, and outcomes of osteonecrosis of the jaw: integrated analysis from three blinded active-controlled phase III trials in cancer patients with bone metastases. Ann Oncol. 2012;23:1341-1347.

27. Fitzpatrick SG, Stavropoulos MF, Bowers LM, et al. Bisphosphonate related osteonecrosis of jaws in 3 osteoporotic patients with history of oral bisphosphonate use treated with single yearly zoledronic acid infusion. J Oral Maxillofac Surg. 2012;70:325-330.

28. Marx RE. Reconstruction of defects caused by bisphosphonate-induced osteonecrosis of the jaws. J Oral Maxillofac Surg. 2009;67(5 Suppl):107-119.

29. Ruggiero S, Dodson T, Fantasia J, et al. American Association of Oral and Maxillofacial Surgeons position paper on medication-related osteonecrosis of the jaw--2014 update. J Oral Maxillofac Surg. 2014;72(10):1938-1956.

30. Aghaloo T, Hazboun R, Tetradis S. Pathophysiology of Osteonecrosis of the Jaws. Oral Maxillofac Surg Clin North Am. 2015;27(4):489-496.

31. Ruggiero SL, Dodson TB, Assael LA, et al. American Association of Oral and Maxillofacial Surgeons position paper on bisphosphonaterelated osteonecrosis of the jaws - 2009 update. Journal of Oral and Maxillofacial Surgery. 2009;67(5):2-12.

32. Ji X, Pushalkar S, Li Y, et al. Antibiotic effects on bacterial profile in osteonecrosis of the jaw. Oral Dis. 2012;18:85-95.

33. Sedghizadeh PP, Kumar SK, Gorur A, et al. Identification of microbial biofilms in osteonecrosis of the jaws secondary to bisphosphonate therapy. J Oral Maxillofac Surg. 2008;66:767-775.

34. Wanger G, Gorby Y, El Naggar MY, et al. Electrically conductive bacterial nanowires in bisphosphonate-related osteonecrosis of the jaw biofilms. Oral Surg Oral Med Oral Pathol Oral Radiol. 2013;115:71-78.

35. Kumar SK, Gorur A, Schaudinn C, et al. The role of microbial biofilms in osteonecrosis of the jaw associated with bisphosphonate therapy. Curr Osteoporos Rep. 2010;8(1):40-48.

36. Wilde F, Heufelder M, Winter $\mathrm{K}$, et al. The role of surgical therapy in the management of intravenous bisphosphonates-related osteonecrosis of the jaw. Oral Surg Oral Med Oral Pathol Oral Radiol Endod. 2011;111:153-163.

37. Mucke T, Koschinski J, Deppe H, et al. Outcome of treatment and parameters influencing recurrence in patients with bisphosphonate- related osteonecrosis of the jaws. J Cancer Res Clin Oncol. 2011;137:907-913.

38. Ngamphaiboon N, Frustino JL, Kossoff EB, et al. Osteonecrosis of the jaw: dental outcomes in metastatic breast cancer patients treated with bisphosphonates with/without bevacizumab. Clin Breast Cancer. 2011;11:252-257.

39. Hayashida S, Soutome S, Yanamoto S, et al. Evaluation of the Treatment Strategies for Medication-Related Osteonecrosis of the Jaws (MRONJ) and the Factors Affecting Treatment Outcome: A Multicenter Retrospective Study with Propensity Score Matching Analysis. J Bone Miner Res. 2017;32(10):2022-2029.

40. Fliefel R, Troltzsch M, Kuhnisch J, et al. Otto: Treatment strategies and outcomes of bisphosphonate-related osteonecrosis of the jaw (BRONJ) with characterization of patients: a systematic review. Int J Oral Maxillofac Surg. 2015;44:568-585. 